\title{
Fire regime changes in the Western Mediterranean Basin: from fuel-limited to drought-driven fire regime
}

\author{
Juli G. Pausas $^{1 *} \&$ Santiago Fernández-Muñoz ${ }^{2}$ \\ (1) CIDE, CSIC, campus IVIA, Montcada, 46113, Valencia, Spain \\ (2) Departamento de Humanidades Historia, Geografia y Arte, Universidad Carlos III, Av. \\ Universidad 22, Colmenarejo 28250, Spain \\ * Corresponding author: J.G. Pausas, URL: http://www.uv.es/jgpausas
}

\begin{abstract}
Wildfires are an integral part of Mediterranean ecosystems; humans impact on landscapes imply changes in fuel amount and continuity, and thus in fire regime. We tested the hypothesis that fire regime changed in western Mediterranean Basin during the last century using time series techniques. We first compiled a 130-yr fire history for the Valencia province (Spain, Eastern Iberian Peninsula, Western Mediterranean Basin) from contemporary statistics plus old forest administration dossiers and newspapers. We also compiled census on rural population and climatic data for the same period in order to evaluate the role of climate and human-driven fuel changes on the fire regime change. The result suggested that there was a major fire regime shift around the early 1970s in such a way that fires increased in annual frequency (doubled) and area burned (by about an order of magnitude). The main driver of this shift was the increase in fuel amount and continuity due to rural depopulation (vegetation and fuel build-up after farm abandonment) suggesting that fires were fuel-limited during the pre1970 s period. Climatic conditions were poorly related to pre-1970s fires and strongly related to post-1970s fires, suggesting that fire are currently less fuel limited and more drought-driven than before the 1970s. Thus, the fire regime shift implies also a shift in the main driver for fire activity, and this has consequences in the global change agenda.
\end{abstract}

Keywords: fire regime changes, Mediterranean ecosystems, land-use changes, fire statistics, ecological thresholds, regime shifts 


\section{Introduction}

Fire regimes have changed throughout the history, specially in relation to changes in climate and human activities (Marlon et al. 2008, Pausas \& Keeley 2009). Humans modified landscapes by changing fuel amount and continuity, and thus fire regimes, since prehistoric days. Early humans used fire for clearing ground to facilitate travel, to kill vermin for hunting, to stimulate regeneration of plant food for both humans and desired herbivores, for expanding human habitat, and for fighting among tribes. Changes in societies (e.g., from native to Europeans, from pre-industrial to post-industrial, etc.) and their associated changes in land use changed fire regimes throughout history in many landscapes (Delcourt \& Delcourt 1997, Guyette et al 2002, Keeley 2002, Pausas 2004, Pausas \& Keeley 2009). Indeed, recent landscape changes, like the increase in density of trees observed in many landscapes as a product of fire suppression and forest plantations, has increased the build-up of fuels and altered fire regimes in many places worldwide (Covington \& Moore 1994, Moritz 2003, Brown et al. 2004, Pausas et al. 2008). Thus, human-caused fuel changes are a significant driver for fire regime changes.

Furthermore, the probability of vegetation to burn is very sensitive to its moisture (fuel flamability), and thus, wildfire are also strongly dependent on climatic parameters (droughts). Consequently, wildfires should be very sensitive to global warming. Indeed, in the Mediterranean Basin, as in most world regions, there is evidence of climatic change, mainly increased temperature (Lebourgeois et al., 2001, Piñol et al. 1998, Esteban-Parra et al. 2003, Pausas 2004) which should have consequences for the fire regime (Piñol et al. 1998, Pausas 2004). Because fire has a very strong effect on vegetation, in many ecosystems changes in fire regime due to global changes may affect plant distribution and ecosystem function more than the direct effect of changes in climate.

However, the relative role of fuel and climate on current fire regimes has been debated (Keeley \& Zedler 2009). There have been recent changes in both human pressure and climate, so fire regime shifts concomitant with changes in the relative role of these two drivers are expected. Indeed, the detection of regime shifts have implications on abrupt changes in ecosystems and it is of crucial importance in the global change agenda (Andersen et al. 2009; Brock \& Carpenter 2010).

Our general hypothesis is that in the Mediterranean Basin fire regimes has shifted during the $20^{\text {th }}$ century, and this shift was associated with the relative importance of the two drivers (human-driven fuel changes and climatic changes). Specifically we predict land-use changes were the main driver of fire regime during part of the history, but current area burnt is mainly driven by climatic conditions related to drought. To test this hypothesis, we documented changes in fire regime in the area of Valencia during the last 130 years, and evaluate the role of land use changes and climate. Because of its location, climate conditions and history, the Valencia region is a good model for most western Mediterranean basin (Millán et al. 1998). The predominance of crown-fires in the Mediterranean Basin preclude the use of fire-scar analysis for fire history estimation; only in small areas where surface-fire has been important, this technique can be successfully applied (Fulé et al. 2008). Consequently, in this paper we compiled fire information from old reports and newspapers to reconstruct a reliable 130-year fire history. By doing so, we provide the best documented fire history for Mediterranean Basin (and probably for any other mediterranean climate area). Specifically we 1) compiled fire history information and rural population census for 130 years in Valencia province; 2) we tested the existence of a fire regime shift and defined two periods (pre/post shift); 3) we quantified and 
compared fire regimes in the two periods; and 4) we related area burnt with changes in rural population and with climatic information.

\section{Methods}

\subsection{Study area}

The study area corresponds the political boundaries of the Valencia province, in the eastern Iberian Peninsula (the Mediterranean coast; Fig. 1). It comprises just over a million hectares, of which $53 \%$ is forest land.

The climate is typically Mediterranean (Pérez-Cueva, 1994) with mild winters and warm and dry summers. The area can be subdivided into two main distinctive bioclimatic zones by temperature: a thermo-Mediterranean zone right next to the coast (mean annual temperature: 17-19 ${ }^{\circ} \mathrm{C}$; vegetative period: 12 months) and a meso-Mediterranean zone (inland area; mean annual temperature $13-17 \circ \mathrm{C}$; vegetative period: $9-11$ months). A third zone, the supraMediterranean area (mean annual temperature: $8-13 \circ \mathrm{C}$ ) is less abundant and appears further inland in the north-western mountains. From the precipitation point of view, most of the area falls in the dry (annual precipitation from 350 to $600 \mathrm{~mm}$ ) and subhumid (from 600 to 1000 $\mathrm{mm}$ ) zones. The annual precipitation regime is strongly bimodal, with precipitation concentrated $(>60 \%)$ in spring and autumn and with a dry summer $(<20 \%$ of the annual precipitation). In the last 50 years, the area shows a significant tendency of increasing temperature, with an average rate of $0.35 \pm 0.05^{\circ} \mathrm{C}$ per decade (Pausas 2004). Changes in precipitation are less obvious due to large interannual variability, although a tendency of decreasing summer precipitation $(-5.21 \pm 3.0 \mathrm{~mm}$ per decade) can be observed (Pausas 2004).

\section{Fire history}

We recorded all evidences of fire from 1873 to 1965 (historic fires) in the Valencia Province after an exhaustive search of historic documents obtained from old Forest Districts records and Dossiers on fires, and from local newspapers. This documents were made available by the Forest Administration of the local Government of Valencia and the Spanish Ministry of Agriculture (Fernández-Muñoz 1999). From this search, we obtained the date, and in most cases $(73 \%)$, the size of 2009 fires. We believe that we were able to record most fires occurring during the studied period, and certainly all large fires; small fires may be underrepresented in our data set. For some years $(1880,1942,1966,1967)$ we were unable to locate reliable fire information, and thus they were excluded from the analysis. We expect that this lack of information would not modify the main results as they corresponds to a small proportion of the whole period considered (1873-2006).

Accurate data for fire occurrence (date and size) for the period 1968 - 2006 were obtained from the Forest Service of the Regional Government of Valencia. During this period the number of fires increased, but there was no trend in area burnt as this was mainly related to interannual climatic variations (Pausas 2004). 
Fires sizes were summed by year (for fires $>10 \mathrm{ha}$ ), to obtain annual area burnt for the whole dataset (1873-2006). For the historical fires with no size information (27\% of the fires), we assigned a size equal to the mean fire size for the historic period (for fire size comparisons only the original fires were considered). We suspect that this is an overestimation of the historic fire size as presumably our historic database is biased towards large fires. So in that sense, the comparison of area burnt between early and late periods is conservative. From the annual area burnt, we tested the existence of fire regime shifts using statistical time series tools. Because these tools usually have low power to detect regime change-points occurring at the extreme of a time series (Andersen et al. 2009), we use two statistical approaches for testing regime shifts: 1) the sequential F test with the proper critical level for sequential tests (MacNeil 1974) and 2) the empirical fluctuation processes (Brown et al. 1975) tested by the cumulative sums of scaled residuals following Ploberger and Kramer (1992; OLS-based CUSUM test). The first approach provides the specific year of the change in fire regime and the associated significance. The two tests were performed with the strucchange package (Zeileis et al. 2002), under the null hypotheses that area burnt remains constant or follows a standard Brownian motion; the departure from the null model would suggest that fire regimes shifted during the study period, and a significant peak inform us of the year of regime shift.

Once the year of the regime shift was known, we split the data by the shift point (first and second period) and computed basic fire statistics (annual number of fires, annual area burnt, mean fire size, etc.), including fire cycle (time for an area equal to the forest land of the Valencia province to burn) for each period. Differences in fire size distribution between the two periods were tested using the Kolmogorov-Smirnov test. Because very small fires were probably not always recorded in historic times, for fire size comparisons we omitted the fires that were less than 10 ha in both datasets. Indeed, for the modern fire statistics, small fires have also been recorded unevenly throughout the years, as the lower size limit for fire to be recorded has varied among years (often 0.5 ha or $1 \mathrm{ha}$ ).

\section{Land use and fire}

We used the official population census for the Valencia province (Instituto Nacional de Estadistica, Spain) to obtain the changes in the rural population density (i.e., population living from agriculture, forests or fishing divided by the current wildland of the Valencia Province) during the 20th century. Changes in rural population are a good estimation (i.e., a proxy) of changes in land use. To indicate any relationship between landscape changes and area burnt, we correlated the changes in the rural population density with the cumulative area burnt over time after a log-log transformation.

\section{Climate and fire}

We located 8 meteorological stations in or around the study area (from the Spanish meteorological network of the Instituto Nacional de Meteorologia) with climatic information going back to the early $20^{\text {th }}$ century (Fig. 1, Table 1). All meteorological stations were located in the coastal area of the eastern Iberian peninsula. All this region has an eastward aspect, that is, towards the Mediterranean Sea, as there is a mountain chain at the west (inland). In fact, meso-meteorological processes during the fire seasons are dominated by east-west (up and downhill) movements of air masses (Millán et al., 2005). The size and topographic structure of this area imply that, in general, interannual climatic variability is very homogeneous throughout the study area; that is, dry periods are dry for the whole region, and the same applies for wet 
periods. In fact, previous analysis showed that, the correlation coefficients of rainfall data among 322 meteorological stations (eastern Iberian peninsula) were positive in $99.5 \%$ and significantly positive $(p<0.05)$ in $80.6 \%$ of cases (Pausas 2004). Consequently the use of meteorological stations outside of the main study area (Fig. 1) does not pose a problem, and allows us to use stations with long records.

We used the summer monthly climatic data to relate with monthly area burnt; these relationships were tested separately for the first and the second period (as defined by the regime shift mentioned above), under the hypothesis that it should be a stronger relationship for the second period than for the first one. Regressions were performed for each meteorological station and considering the area burnt as $\log _{10}$ (area burnt +1$)$. This transformation was performed because fire is a spreading process and thus the relation between climate and area burnt is not expected to be linear, but exponential. Furthermore, the log-transformation reduced the skewness of the frequency distribution of the area burnt.

\section{Results}

We recorded a total of 9399 fires for the 130 year fire history of the Valencia province (Figure 2); 8850 of these fires had fire size information, and 1251 were larger than 10 ha. The empirical fluctuation function suggested that there is a significant peak in fire regime change around 1970 $(\mathrm{S}=2.077, \mathrm{p}=0.00035$, CUSUM test; Fig. 3). The sequential $\mathrm{F}$ statistic also suggested a significant shift located at the year 1972 (sup.F $=27.15$, $p<0.00001$; Fig. 3). Therefore we split the fire history data by the year 1972 (i.e., 1873-1972 and 1973-2006).

There were clear differences in fire statistics between the first (pre-1973) and the second (post1972) period (Table 2). Mean annual number of fires doubled, while mean annual area burnt increased by an order of magnitude, from the first to the second period. The association between number of fires and area burnt showed a significant logarithmic relationship for both periods (number of fires-area burnt: $F_{1,109}=275.1, p<0.00001$; effect of the period: $F_{1,109}=5.14$, $p=0.025$; no interaction effect). Fires tend to be larger in the second period (Table 2). Fire size distribution of the second period is more right-skewed than the one for the first period, that is, the proportion of small fires is higher in the first period, while the proportion of large fires is higher in the second period (Fig. 4). Indeed, no fire larger than 6000 ha was recorded during the 95 years previous to 1972, but in the subsequent 33-year period, 11 fires were larger than that size and the largest fire burned over $28000 \mathrm{ha}$. As a consequence of all these fire statistics, the fire cycle was also estimated to be very different between the two periods, about an order of magnitude different (397 and 49 years, for the first and the second periods, respectively).

The changes in fire regime along the $20^{\text {th }}$ century were concomitant with a reduction in the use of the land (Fig. 2), as can be inferred from the strong negative relationship between the rural population and the accumulated area burnt $\left(r=-0.925, p=0.0001\right.$; Fig. 5). While in the late $18^{\text {th }}$ century and early $19^{\text {th }}$ century the rural population density was over 1 inhabitant $/$ ha $(70 \%$ of the population was rural), this value decreased to ca. $0.6(20 \%)$ in 1970 and to $0.2(5.7 \%)$ in 2001 (Fig. 5).

For the 8 meteorological stations with historical data, summer climatic parameters and summer area burnt were weakly related or unrelated for the first period (pre-1973) (Table 3). However, 
for the same stations, climate was strongly related to the area burnt during the second period (post-1972), and for all stations (Table 3).

\section{Discussion}

We reconstructed the longest published fire history (including fire size) for an extensive area dominated by crown-fire ecosystems in the Mediterranean basin. The only longer fire history for a Mediterranean basin was compiled in a surface-fire regime ecosystem, at forest patch scale, and without considering fire size (170 years, Fulé et al. 2008). Our data unambiguously demonstrate a change in fire regime during the 70's and that this change is associated with rural exodus (Figures 2, 3 and 5). This change in fire regime is close to the year in which the type of data available changed from historic data from old records to systematically recorded fires by government agencies, and thus doubts could arise about whether the results are a methodological artifact. Certainly the technology available during the early $20^{\text {th }}$ century did not provide precise data on burnt areas, but we are confident that all large fires were certainly depicted. Indeed, the study region was highly populated during the study period and fires were social alarms as suggested by the emphasis in the newspapers (Fernández-Muñoz 1999). Furthermore, the magnitude of the difference in fire sizes and the frequency of large fires is so large (see Figure 2), that it rules out any possible differences in methodology. In addition, we have assumed several conservative criteria for fire size comparisons (see methods). The changes in fire regime are so strong, that even if we would increase the historic fire data (occurrence and area burned) by an additional $25 \%, 50 \%$ or even $100 \%$ (which would certainly be a strong overestimation), the fire regime change would still be unambiguous (e.g., doubling the area burnt during the first period the results do not change: CUSUM test: $\mathrm{S}=1.82, \mathrm{p}=$ 0.003; seq F test: sup.F $=19.97, p=0.00023$, breakpoint= 1972). Even we are confident with the data for the purpose used here, it is important to consider some of their caveat. The period with the highest density of fires without fire size (see upper x-axis in Fig. 2) correspond to the Spanish Civil War (1936-1939). During this period the number of fires recorded (106 fires) was close to the mean number of fires for randomly selected 4-years periods during the historical data (mean $=90$ fires); however the information on fire size was only for $45 \%$ of the fires (compared with $73 \%$ for the rest of the period). Although for computing the fire statistics, we assigned the mean fire size for the historic period, the error for these 4 years is more important than for the rest of the period; however, this period is relatively small to the total time series and should not modify the trends observed. In addition, there were few years without data (Fig. 2 ), but this lack of information on a reduced number of years should not change the main trend observed. In any case, the obtained fire history is the best available for the study area and for any European and Mediterranean area. The inspection of Figures 2 and 5 (inset) suggest a possible second shift in fire regime during the last 10 years towards a reduction of fire activity; however it was too short to be statistically detected. This possible shift seems to be more related to current strong fire-prevention and suppression policies (i.e., temporally low fire activity) than changes in fuel structure or climate. The role of this trend should be evaluated in the future when a longer time serie will be available.

Fires increased in frequency and especially in size after the 70s (Table 2, Fig. 2 and 4). This trend is very different from the climatically similar zone of California were there is no evidence of changes in fire regime during the same time period (Keeley \& Zedler 2009). This striking difference is most probably due to the marked differences in the recent human history between the two regions and the concomitant impact on the landscapes (much longer and intense in the Mediterranean Basin than in California). The fire regime change in the Mediterranean Basin was not gradual but sudden (Fig. 3), and cannot be explained by the gradual climatic changes 
observed in the study area (Pausas 2004); changes in fuel conditions need to be considered. The turning point seems to be related to a critical threshold in landscape connectivity (Turner \& Garner 1991, With \& Crist 1995). This change in fire regime can be explained by the abandonment of agriculture and livestock, and the change in the domestic energetic sources (from wood to others). In fact, in the Mediterranean basin, the main current ecological process at landscape scale is the recovery after land abandonment (Bonet \& Pausas 2007), with very flammable vegetation at the early successional stages (Baeza et al. 2011). Concomitant to this land abandonment, was the trend of afforesting this oldfields, mainly with conifers (Pausas et al. 2008). All these factors increased the biomass connectivity of landscapes allowing fires to spread (i.e., to percolate, in the terminology of landscape ecology, Turner \& Garner 1991) further and thus increase in size. In addition, the increase in population and in the wildlandurban interface increased fire ignitions (e.g., Keeley et al. 1999).

Although land abandonment was gradual, as the changes in climate, the implications at the landscape scale were not gradual and showed spatial nonlinearities (Fig. 5). The propagation of fine-scale changes (gradual land abandonment) generates networks of connectivity at broader spatial scales including thresholds governing the rate of change (Peters et al. 2004). Spatial simulation (not shown) suggest that for a given constant rate of abandonment, the mean patch size and the size of the largest patch increase exponentially with time, in a similar manner that habitat suitability for species with short-dispersal decrease exponentially with fragmentation (Ovaskainen et al. 2002). These large interconnected patches provide the food for large fires. In addition, fire itself is also an spatial process generating positive feedbacks, and thus when fuel is available (highly connected), it spread rapidly crossing thresholds and generating unexpected large burnt areas (Peters et al. 2004). This increase in fire frequency and size was produced despite the increased fire extinction technology and budget (Seijo 2009). The critical landscape threshold seems to be when rural population was about 0.6 inhabitants/ha (i.e, ca. 1970). There is a coincidence in the critical point inferred by the regime shift statistics (Fig. 3) and the population-area burnt relationship (Fig. 5). Given that there is a time delay for the vegetation to grow on abandoned land, the landscape threshold would be associated to rural population threshold higher than 0.6 inhabitants/ha. These thresholds switched from a fuel-limited fire regime to a drought-driven fire regime.

When fuel was not the main limiting factor for fire (after 1970s), then area burnt was strongly dependent on dry climatic conditions (Keeley and Fotheringham 2001, Piñol et al. 1998, Pausas 2004, Table 4, Fig. 6). Indeed, pre-1973 fires were weakly related to climate, while post-1972 fires are strongly related to climatic parameters related to drought (high temperature and low precipitation). Pausas (2004) also demonstrated significant fire-climate relationships during the recent decades in the same study area.

In summary, global change greatly affects fire regimes through land use changes. The changes in land use (land abandonment and forest plantations) during the 1970s was responsible of the increase in fire size and in the frequent of large fires, suggesting that fire was fuel-limited previously to the 1970s. However, during the last few decades of the $20^{\text {th }}$ century, fuels have been available and the area burnt is strongly driven by dry conditions, which in turn, are predicted to become more frequent and intense. 
Acknowledgements. We thank R. Currás, from the Forests Service of Valencia, for providing access to information on historic fires, and J. Miro (CEAM) for his kind help on the management of climatic information. CIDE is supported by CSIC, Generalitat Valenciana and Universitat de Valencia.

\section{References}

Andersen T, Carstensen J, Hernández-García E, Duarte CM (2009) Ecological thresholds and regime shifts: Approaches to identification. Trends Ecol Evol 24 (1):49-57

Baeza J, Santana VM, Pausas JG. Vallejo R (2011). Successional trends in standing dead biomass in Mediterranean Basin species. J. Veget. Sci., in press.

Bonet A, Pausas JG (2007) Old field dynamics on the dry side of the Mediterranean Basin: Patterns and processes in semiarid SE Spain. In: Cramer VA, Hobbs RJ (eds) Old fields: Dynamics and restoration of abandoned farmland. Island Press, Washington, DC, pp 247-264

Brock W, Carpenter S (2010) Interacting regime shifts in ecosystems: Implication for early warnings. Ecol Monogr. doi:10.1890/09-1824

Brown RL, Durbin J, Evans JM (1975) Techniques for testing the constancy of regression relationships over time (with discussion). J R Statist Soc:149-192

Brown TJ, Hall BL, Westerling AL (2004) The impact of twenty-first century climate change on wildland fire danger in the Western United States: An applications perspective. Clim Change 62 (1):365-388

Covington WW, Moore MM (1994) Southwestern ponderosa forest structure: Changes since euro-american settlement. J For 92 (1):39-47

Delcourt HR, Delcourt PA (1997) Pre-columbian native american use of fire on southern Appalachian landscapes. Conserv Biol 11 (4):1010-1014

Esteban-Parra MJ, Pozo-Vázquez D, Rodrigo FS, Castro-Díez Y (2003) Temperature and precipitation variability and trends in northern Spain in the context of the Iberian peninsula climate. In: Bolle HJ (ed) Mediterranean climate: Variability and trends. Springer, Berlin, pp 259-276

Fernández-Muñoz S (1999) Cambio y continuidad en los incendios forestales: Estudio de casos en las provincias de Soria y Valencia. In: Aranque E (ed) Incendios históricos. Una aproximación multidisciplinar. Universidad Internacional de Andalucía, pp 111-148

Fulé PZ, Ribas M, Gutiérrez E, Vallejo R, Kaye MW (2008) Forest structure and fire history in an old Pinus nigra forest, eastern spain. For Ecol Manage 255 (3-4):1234-1242

Guyette RP, Muzika RM, Dey DC (2002) Dynamics of an anthropogenic fire regime. Ecosystems 5 (5):472-486

Keeley JE (2002) Native American impacts on fire regimes of the California coastal ranges. J Biogeogr 29:303-320

Keeley JE, Fotheringham CJ (2001) Historic fire regime in southern California shrublands. Conserv Biol 15 (6):1536-1548

Keeley JE, Fotheringham CJ, Morais M (1999) Reexamining fire suppression impacts on brushland fire regimes. Science 284 (5421):1829-1832

Keeley JE, Zedler PH (2009) Large, high intensity fire events in southern California shrublands: Debunking the fine-grained age-patch model. Ecol Appl 19:69-94

Lebourgeois F, Granier A, Breda N (2001) Une analyse des changements climatiques régionaux en france entre 1956 et 1997. Réflexions en terme de conséquences pour les écosystems forestiers. Ann For Sci 58 (7):733-754

MacNeill IB (1974) Tests for change of parameter at unknown times and distributions of some related functionals on Brownian motion. Annals of Statistics 2 (5):950-962 
Marlon JR, Bartlein PJ, Carcaillet C, Gavin DG, Harrison SP, Higuera PE, Joos F, Power MJ, Prentice IC (2008) Climate and human influences on global biomass burning over the past two millennia. Nature Geoscience 1 (10):697-702

Millán MM, Estrela MJ, Sanz MJ, Mantilla E, Martín M, Pastor F, Salvador R, Vallejo R, Alonso L, Gangoiti G (2005) Climatic feedbacks and desertification: The Mediterranean model. J Clim 18 (5):684-701

Moritz MA (2003) Spatiotemporal analysis of controls on shrubland fire regimes: Age dependency and fire hazard. Ecology 84 (2):351-361

Ovaskainen O, Hanski I (2001) Spatially structured metapopulation models: Global and local assessment of metapopulation capacity. Theor Popul Biol 60:281-302

Pausas JG (2004) Changes in fire and climate in the eastern Iberian peninsula (Mediterranean Basin). Clim Change 63 (3):337-350

Pausas JG, Keeley JE (2009) A burning story: The role of fire in the history of life. Bioscience 59 (7):593-601. doi:10.1525/bio.2009.59.7.10

Pausas JG, Llovet J, Rodrigo A, Vallejo R (2008) Are wildfires a disaster in the Mediterranean Basin? - a review. Int J Wildland Fire 17 (6):713-723

Pérez Cueva AJ (1994) Atlas climàtic de la Comunitat Valenciana (1961-1990). Generalitat Valenciana, Valencia

Peters DPC, Pielke RA, Bestelmeyer BT, Allen CD, Munson-McGee S, Havstad KM (2004) Cross-scale interactions, nonlinearities, and forecasting catastrophic events. Proc Natl Acad Sci USA 101 (42):15130-15135

Piñol J, Terradas J, Lloret F (1998) Climate warming, wildfire hazard, and wildfire occurrence in coastal eastern Spain. Clim Change 38:345-357

Ploberger W, Kramer W (1992) The CUSUM test with OLS residuals. Econometrica 60 (2):271-285

Seijo F (2009) Who framed the forest fire? State framing and peasant counter-framing of anthropogenic forest fires in Spain since 1940. Journal of Environmental Policy \& Planning 11:103-128

Turner MG, Gardner RH (1991) Quantitative methods in landscape ecology. Ecological studies. Springer,

With KA, Crist TO (1995) Critical thresholds in species' responses to landscape structure. Ecology 76 (8):2446-2459

Zeileis A, Leisch F, Hornik K, Kleiber C (2002) Strucchange: An R package for testing for structural change in linear regression models. J Stat Soft 7 (2):1-38 
Table 1. Location of the eight meteorological stations considered for relating fire and climate in the pre-1965 period, and the initial year with temperature and precipitation data.

\begin{tabular}{clcccc} 
code & Station & Lat & Long & $\mathrm{T}$ & $\mathrm{P}$ \\
\hline 1 & Tortosa (Obser. del Ebre) & 40.82 & 0.49 & 1910 & 1910 \\
2 & Atzeneta & 40.22 & -0.17 & 1943 & 1943 \\
3 & Valencia (Vivers) & 39.48 & -0.38 & 1937 & 1921 \\
4 & Utiel & 39.57 & -1.2 & 1942 & 1948 \\
5 & Ontinyent (Col·legi) & 38.82 & -0.6 & 1940 & 1950 \\
6 & Alacant (Ciutat Jardí) & 38.37 & -0.5 & 1938 & 1938 \\
7 & Torrevieja (Laguna de) & 37.98 & -0.7 & 1927 & 1927 \\
8 & Murcia (Beniajan) & 37.97 & -1.07 & 1933 & 1933 \\
\hline
\end{tabular}

Table 2. Fire statistics for the first (1873-1972) and the second period (1973-2006). All statistics are based on the fires statistics without considering fires smaller than 10 ha (except number of fires in the data and number of fires with no size information).

\begin{tabular}{lcc}
\hline & First period & Second period \\
\hline Period & $1873-1972$ & $1973-2006$ \\
\# years with data & 95 & 33 \\
\# fires in the data & 2186 & 7213 \\
\# fires with no size information & 549 & 0 \\
\# fires ( $>10$ ha) & 1085 & 715 \\
Mean annual \# fires & 11.42 & 21.67 \\
Mean annual area burnt (ha) & 1433.8 & 11248.7 \\
Fire size (ha) & & \\
$\quad$ Mean (>10 ha) & 125.54 & 534.9 \\
$\quad$ Mean (>100 ha) & 587.54 & 1444.23 \\
$\quad$ Max & 6000 & 28310 \\
Fire size distribution (\%) & & \\
10-100 ha & & 64.62 \\
$\quad$ 1000 ha & 71.64 & 8.25 \\
Fire cycle (yr) & 3.54 & 49 \\
\hline
\end{tabular}


Table 3. P-values of the relationship between monthly summer area burnt (log-transformed) and the three summer climatic variables (P, Tmean and Tmax) for the two studied periods, for eight Meteorological stations. In all cases were the relation is significant, it is negative with precipitation and positive with both mean and maximum temperatures. Number of years with both climatic and fire data is indicated in brackets. ns: $p>0.1$

\begin{tabular}{|c|c|c|c|c|c|c|c|}
\hline \multirow{2}{*}{\multicolumn{2}{|c|}{ Station }} & \multicolumn{3}{|c|}{ 1873-1972 } & \multicolumn{3}{|c|}{$1973-2006$} \\
\hline & & $\mathrm{P}$ & $\mathrm{T}$ mean & $\mathrm{T} \max$ & $\mathrm{P}$ & $\mathrm{T}$ mean & $\mathrm{T} \max$ \\
\hline 1 & Tortosa & $0.003(58)$ & $0.04(33)$ & $0.03(33)$ & $0.06(34)$ & $<0.0001(34)$ & $<0.0001(34)$ \\
\hline 2 & Atzaneta & ns (28) & ns (28) & ns (28) & $0.04(34)$ & $<0.0001(34)$ & $<0.0001(34)$ \\
\hline 3 & Valencia & ns (32) & $0.004(32)$ & ns (32) & $0.003(34)$ & $0.001(34)$ & $0.001(34)$ \\
\hline 4 & Utiel & $0.04(23)$ & ns (27) & ns (27) & $0.009(34)$ & $<0.0001(34)$ & $<0.0001(34)$ \\
\hline 5 & Ontinent & ns (21) & ns (29) & ns (29) & $0.0003(34)$ & $<0.0001(34)$ & $<0.0001(34)$ \\
\hline 6 & Alacant & ns (31) & $0.02(31)$ & $0.008(31)$ & $0.002(34)$ & $0.002(34)$ & $<0.0001(34)$ \\
\hline 7 & Torrevieja & ns (35) & ns (35) & $<0.0001(35)$ & $0.0009(34)$ & $0.003(34)$ & $<0.0001(34)$ \\
\hline o & Murcia & ns (37) & $<0.0001$ (35) & $<0.0001(35)$ & $0.01(34)$ & $<0.0001(33)$ & $<0.0001(33)$ \\
\hline
\end{tabular}



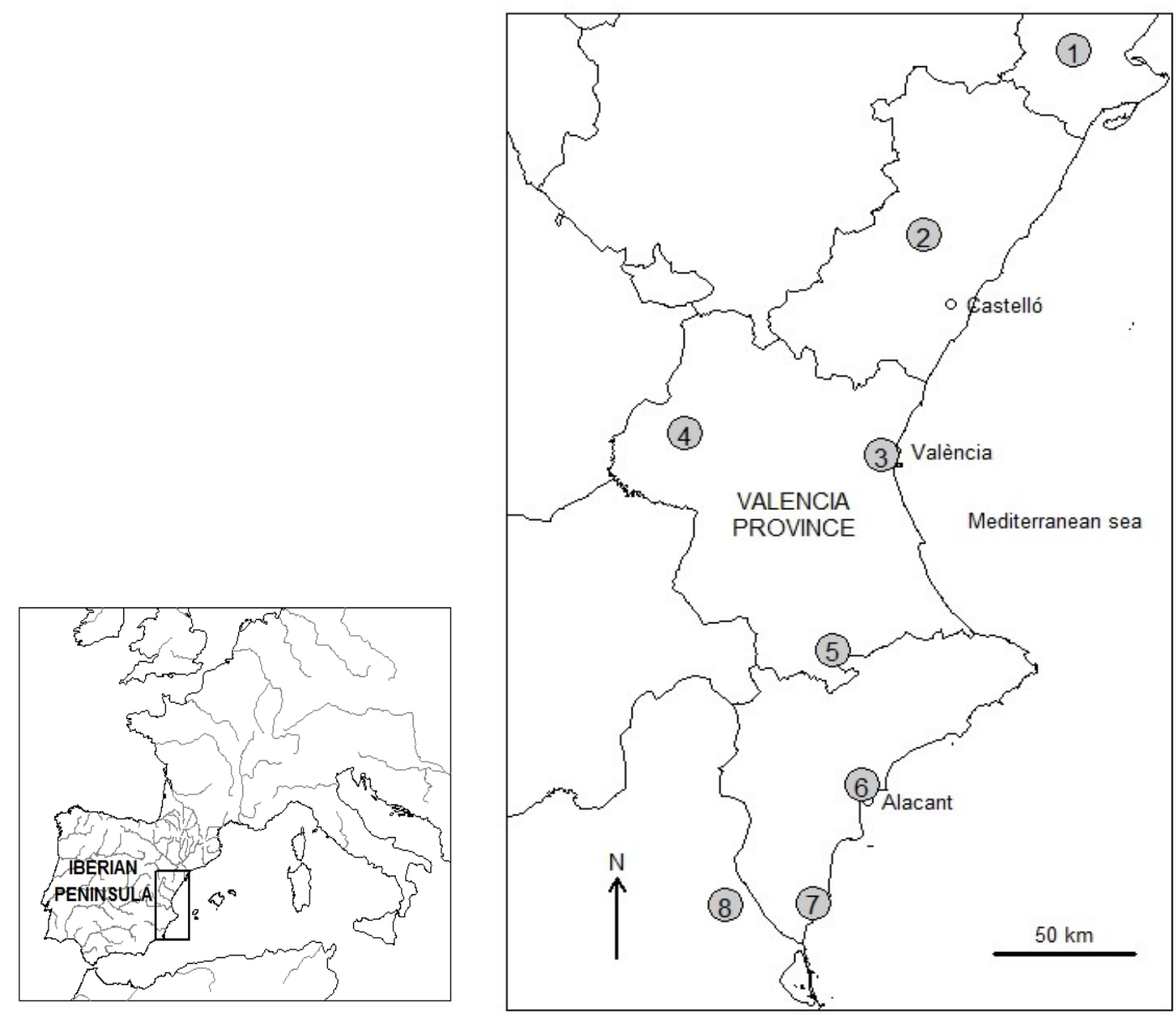

Figure 1. Location of the study area in the eastern Iberian Peninsula and location of the 8 meteorological stations (circled numbers; see Table 1). Limits are provincial boundaries and the Valencia province is in the middle. 


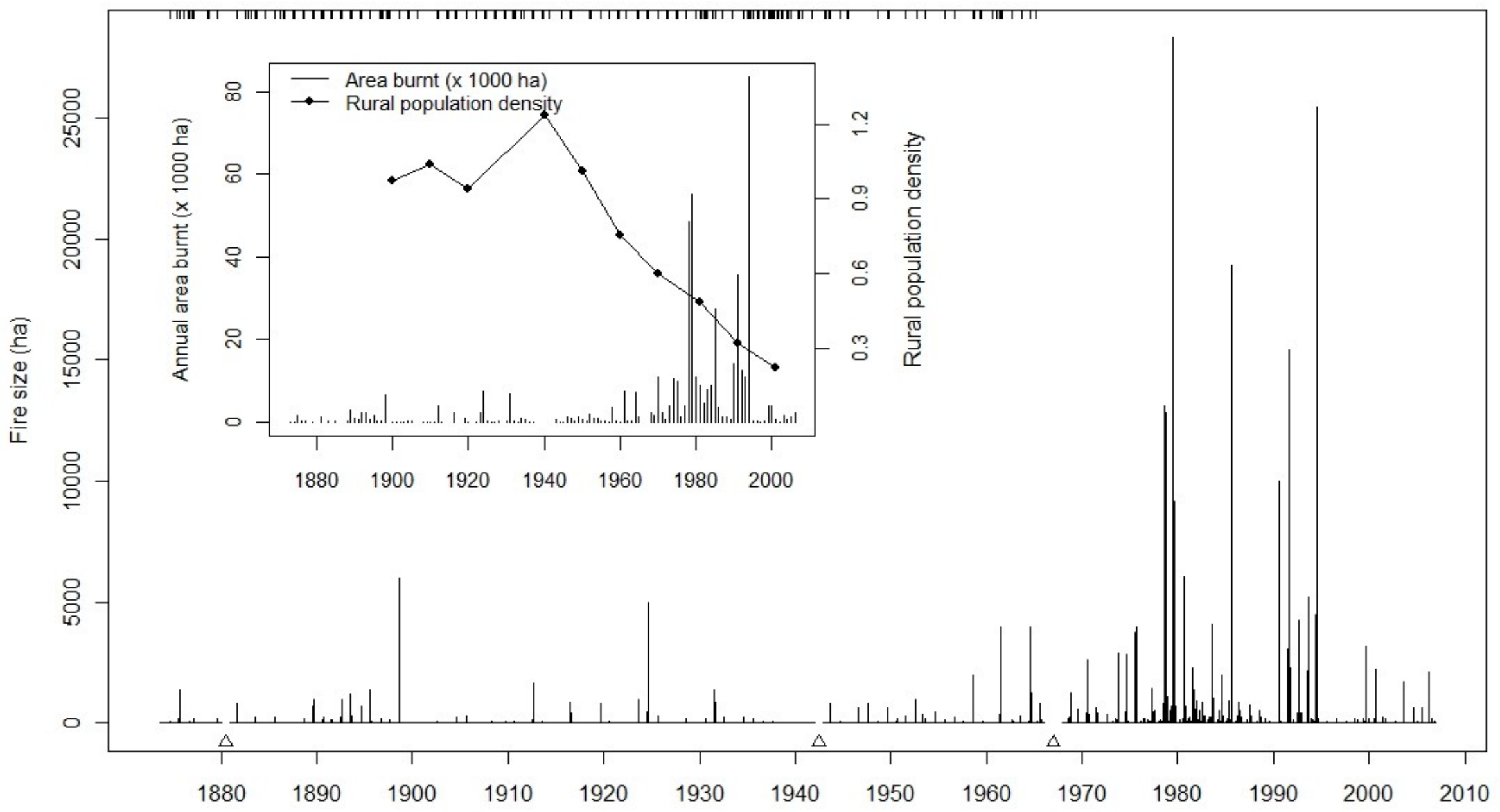

Figure 2. Fire occurrence and size (in ha) in the Valencia province for all the period available (1873-2006). Triangles in the lower $x$-axis indicate the periods without data; ticks in the upper x-axis indicate fires of unknown size. Inset figure: annual area burnt (ha x 1000, vertical lines) for the same period and region and the rural population density (inhabitants/ha); for computing annual area burnt, fires without size data are given the value of the average fire size during the historical period (1873-1965). 


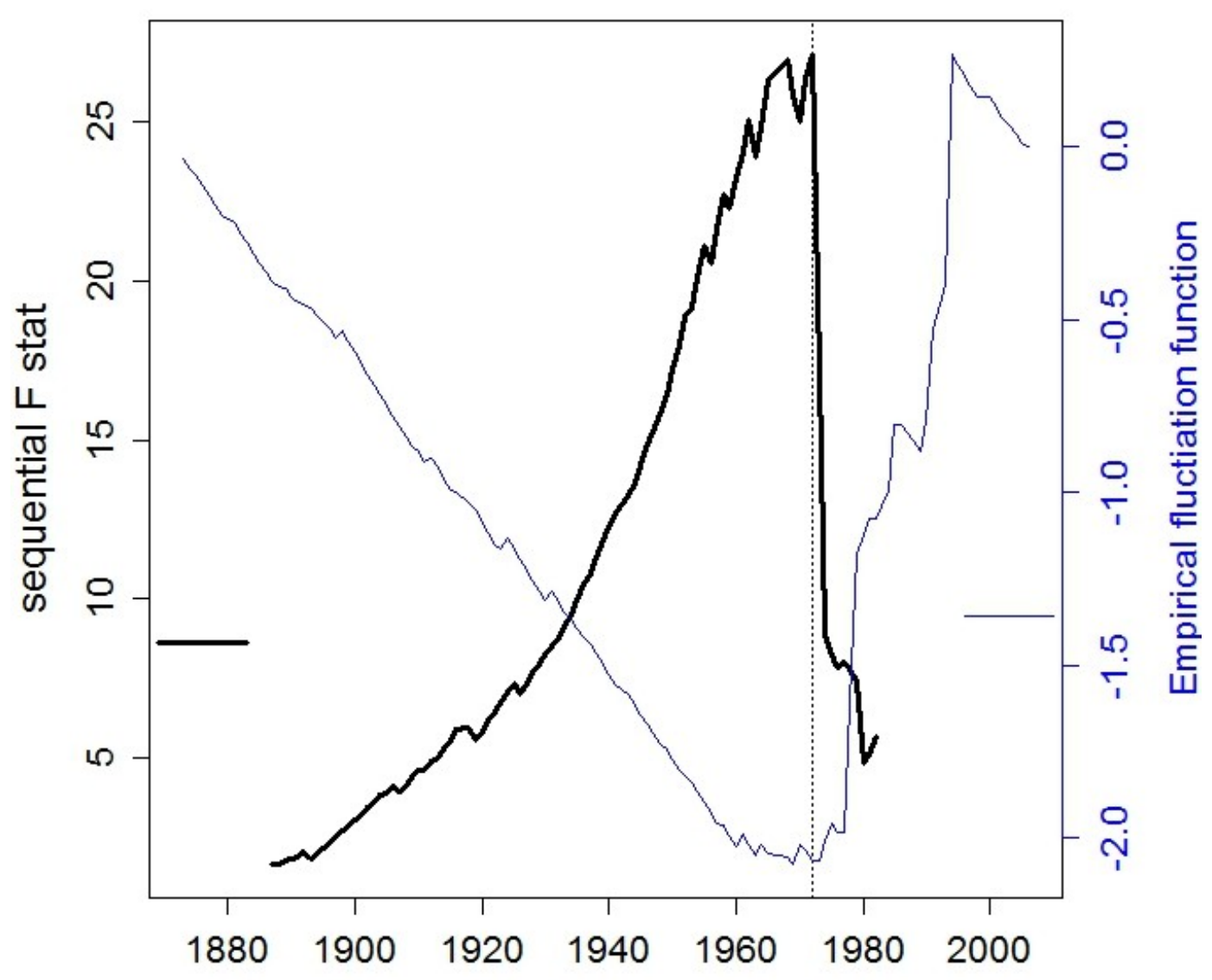

Fig. 3. Sequential F statistic (thick line, left y-axis) and empirical fluctuation function (thin line, right $y$-axis) on annual area burned. Both tests significantly depicted a regime shift around $1970(p<0.001)$. The horizontal lines next to the $y-$ axes define the limit of significance (at $\mathrm{p}=0.05$ ) for the test of the corresponding axis: F values greater than 8.63 and values of the empirical fluctuation function lower than -1.358 suggest significant shifts. 


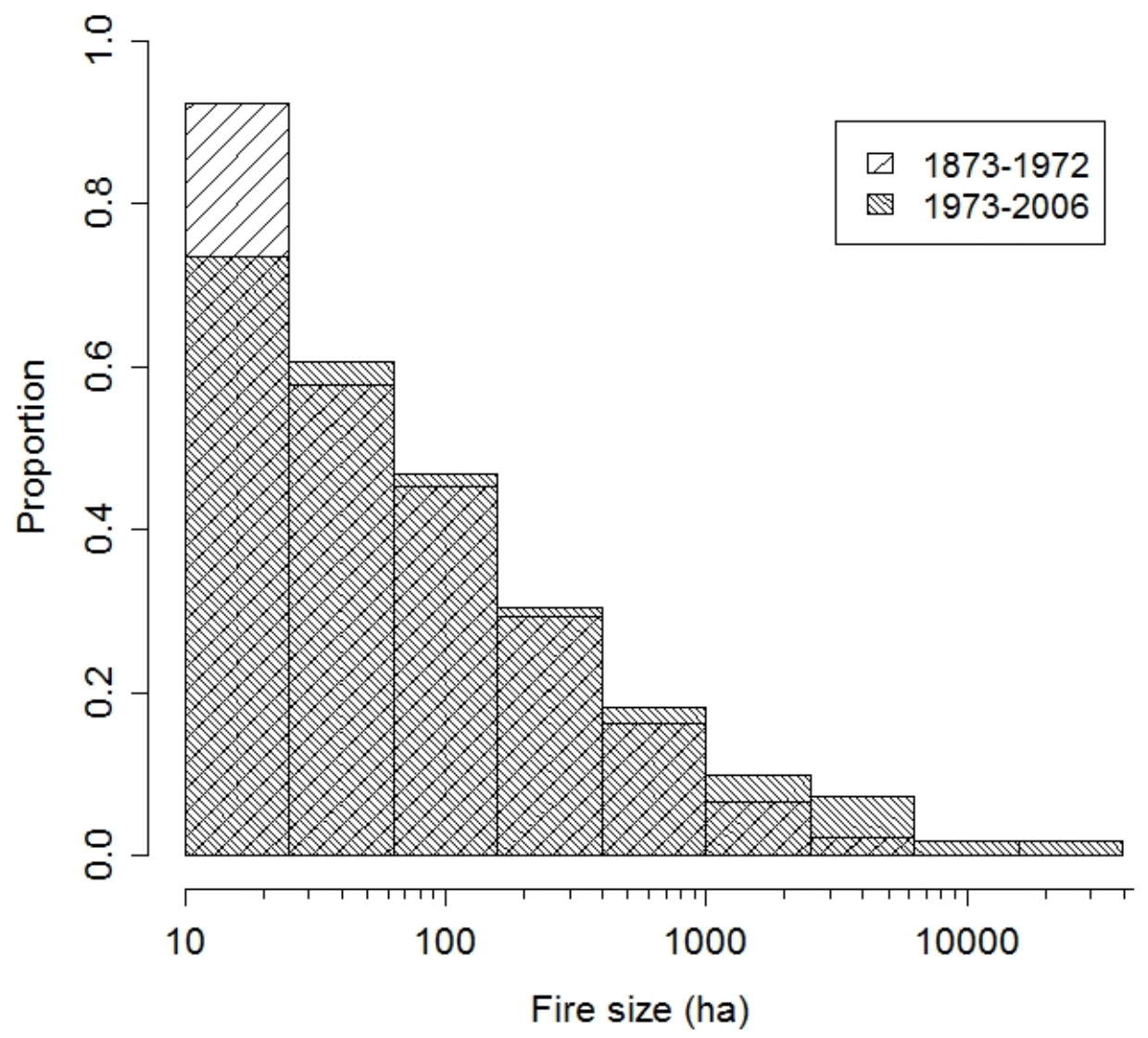

Fig. 4. Fire size frequency distribution in the two studied periods. The two frequency distributions are significantly different (Kolmogorov-Smirnov tests, $\mathrm{p}=$ $0.05)$. 


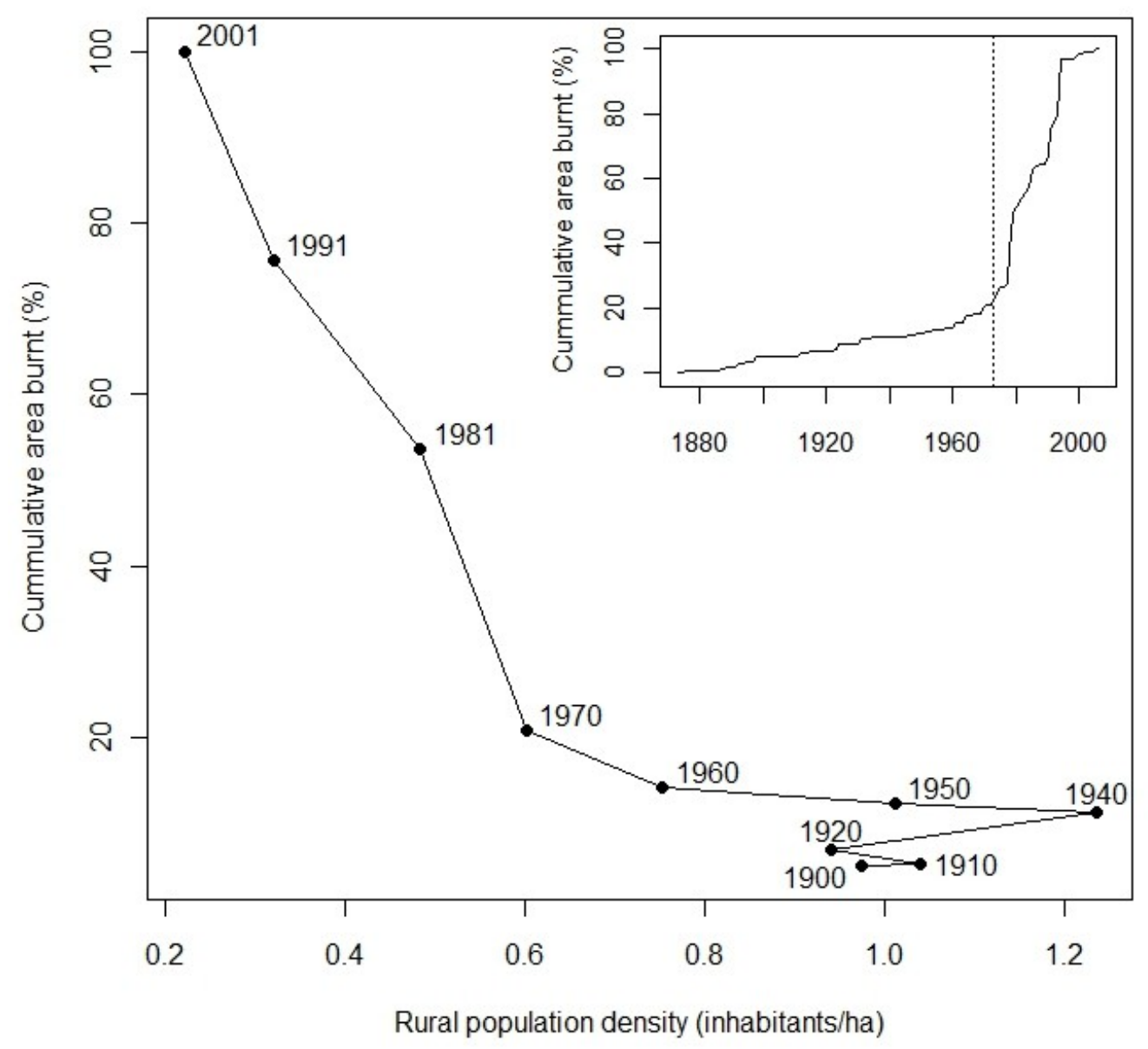

Fig. 5. Relation between the rural population density (inhabitants/ha) and the cumulative area burnt $(\%)$ during the $20^{\text {th }}$ century in the Valencia region (see also inset in Fig. 2). The relation is strongly significant $(r=-0.925, p=0.0001, \log -\log$ transformation). The inset figure shows the cumulative area burnt (\%) for the studied period (vertical dotted line in 1972/73). 